\title{
DE COMPOSITIONE VERBORVM: APONTAMENTOS PARA UMA REAVALIAÇÃO DO TRATADO DE DIONÍSIO DE HALICARNASSO
}

\author{
GIULIANA RAGUSA* \\ Faculdade de Filosofia, Letras e Ciências Humanas \\ da Universidade de São Paulo
}

\begin{abstract}
RESUMO: Este trabalho é norteado por três objetivos: a apresentação do De Compositione Verborum e de Dionísio de Halicarnasso, a discussão de algumas questões referentes à crítica do tratado, e a problematização de conceitos como literatura, retórica e crítica literária. Justifica o primeiro objetivo a escassez de estudos, no Brasil, sobre esse tratado que tanto despertou a atenção de homens como Racine, Boileau, e de helenistas, sobretudo europeus. O segundo objetivo faz-se relevante devido ao desconforto gerado pela leitura da fortuna crítica sobre o tratado, na qual revelam-se cobranças questionáveis a estudos como os de Dionísio, sinal de um certo desajuste entre expectativas atuais e necessidades da época. O terceiro objetivo se impõe na medida em que aquele desconforto mostra-se decorrente, dentre outras coisas, do emprego problemático de conceitos modernos no estudo de textos antigos. Cumpridos os objetivos propostos, pode-se, enfim, repensar e reavaliar o tratado de Dionísio, ressaltando-lhe as qualidades e contribuições.
\end{abstract}

PALAVRAS-CHAVE: Dionísio de Halicarnasso; De compositione uerborum; retórica; literatura; crítica.

\section{Introdução}

Em carta de 1693 a Boileau, Racine refere-se a Dionísio de Halicarnasso (DH), resumindo assim o assunto do tratado De compostione uerborum (De comp.): "Denys d'Halicarnasse (...) fait cette réflexion, que ce n'est point le choix des mots qui en fait l'agrément, (...) mais qu'ils ne laissent pas de charmer par la manière dont le poète a eu soin de les arranger". Após alguns comentários, mostra-se entusiasmado: "Tout ce traité de Denys d'Halicarnasse dont je viens de vous parler, et que je relus hier tout entier avec un grand plaisir (...) ". ${ }^{1}$ Esse entusiasmo não aparece apenas nessa carta de Racine, mas, ao contrário, e 
embora por vezes seguido de frustração, tal sentimento está presente em boa parte da fortuna crítica do tratado de DH. Por quê?

Essa indagação, à primeira vista dispensável e irrelevante, suscita várias outras. Por que a leitura do De comp. anima e decepciona? Que expectativas envolvem sua leitura, e o que se espera encontrar em DH? Poderemos, com tranqüilidade, chamar DH de "crítico literário", e cobrar-lhe o que se cobra de um crítico hoje? Ao falarmos em literatura, crítica, teoria e história literárias - disciplinas que só se especializaram recentemente -, não tentamos realizar uma modernização dos antigos, já pretendida pelo Romantismo do século XIX (cf. Dupont, 1994, p. 7)? Que prejuízos as traduções interpretativas/modernizantes acarretam a certos termos gregos do tratado De comp.?

Cada pergunta dessas pode, isoladamente, render inúmeras reflexões; gastouse e gasta-se muita tinta para tratar da crítica literária antiga e de figuras como $\mathrm{DH}$, 'Longino', e tantos outros. Dadas as limitações próprias de sua natureza, este trabalho buscará refletir sobre aquelas questões - ou parte delas -, tecendo um comentário geral que seguirá três etapas: 1) leitura comparativa de algumas obras significativas sobre DH e seu tratado; 2) consideração da retórica e da literatura; 3) leitura dirigida, por assim dizer, do tratado, retomando os pontos relevantes da discussão dos itens anteriores. Deseja-se, concluído esse percurso, fundamentar as indagações acima colocadas e, talvez, encontrar suas raízes e possíveis respostas.

\section{Dionísio de Halicarnasso e o De compostione uerborum aos olhos da crítica}

\section{- um panorama das visões sobre Dionísio de Halicarnasso:}

As opiniões a respeito de $\mathrm{DH}$, que viveu em Roma por volta de 30 a.C., são unânimes em reconhecer a obra que ele nos legou, mas não o são quando se trata de avaliar suas qualidades e seus defeitos, bem como sua importância. $O$ quadro a seguir, cronologicamente organizado para que sejam ressaltadas as recorrências e variações, citará algumas obras a fim de ilustrar as visões críticas sobre DH.

Publicado em 1902, Denys d'Halicarnasse, de M. Egger, abre-se com uma espécie de biografia reconstruída de Dionísio - a respeito de quem pouco se sabe, ou quase nada - que introduz uma ampla apreciação de sua obra conhecida. Há até mesmo, em "Denys artiste et écrivain dans ses oeuvres littéraires", um comentário sobre a redação de DH: "Composer n'est pas le souci de Denys dans ses oeuvres littéraires (...)" (Egger, 1902, p. 235). E adiante: "Malgré leur composition lâche et rapide, les traités littéraires renferment donc les pages chaleureuses et d'un gôut délicat: il y a là quelque chose de personnel qui fait honneur à Denys." (id., 1902, p. 243). 
Reafirmando um dos consensos quando se trata de DH, Egger, já no começo do século XX, definia-o como um mestre particular de retórica e gramática a serviço das famílias romanas aristocráticas. Considerando-o demasiado reservado quanto a si, atribui-lhe pouca imaginação e frieza, embora o julgue "apaixonado por seu ofício" (id., 1902, p. 15). Assim, DH é erudito, judicioso, mas seco; instrutivo, mas dogmático.

Em 1934, J. W. H. Atkins publicou Literary Criticism in Antiquity: a sketch of its development, ${ }^{2}$ em dois volumes - Greek e Graeco-Roman. Obra de referência, trata-se de um esboço histórico da crítica literária de Homero aos séculos I-II d.C. Muitos repetirão, com poucas alterações, essa cronologia, em busca das origens e das chaves para a crítica moderna - ansiedade comum a boa parte dos helenistas.

No volume II, em "Classicism and Prose Style: Dionysios of Halicarnassus", Atkins classifica DH como a maior autoridade em teoria da retórica na Roma de Augusto, porém não o poupa, apontando como seus defeitos lacunas ocasionais em julgamentos decorrentes, muitas vezes, de um olhar troppo técnico; o emprego de fórmulas retóricas prontas; a secura, o pedantismo eventual; o tom escolástico; o desequilíbrio nas análises - ora descuidadas, ora demasiadamente elaboradas -; a minimização do papel do gênio na confecção artística das obras em benefício da valorização excessiva da técnica - crítica carregada de ideologia romântica. Como qualidades, Atkins destaca a sensibilidade de $\mathrm{DH}$, sua percepção, seu vocabulário crítico e gosto estético.

Wimsatt e Brooks publicaram em inglês no ano de 1957, Crítica Literária. Breve História, outro estudo histórico, mas com diferenças, a começar pelo período que cobre: de Platão ao século XX. DH é citado como um crítico retórico poucas vezes.

G. Grube, em The Greek and Roman Critics, 1965, considera DH um "homem de letras" (Grube, 1965, p. 208), mais um tutor do que um rhetor, e aponta, valorizando, dois traços que seriam comuns aos tratados: a seu ver, $\mathrm{DH}$ evita ser muito técnico e procura diferenciar seus trabalhos dos manuais típicos de retórica.

Dois anos depois, W. B. Stanford publica The Sound of Greek. Studies in the Greek Theory and Practice of Euphony, sobre o papel do som na literatura grega. Para ele, DH é um professor de retórica que escreveu o "celebrado tratado" (Stanford, 1967, p. 15) De comp.

Em The Art of Rhetoric in the Roman World, de 1972, G. Kennedy conclui seguindo o consenso - que $\mathrm{DH}$ foi tutor de filhos da aristocracia romana, aos quais ensinava gramática e retórica, embora dessa última só lhe interessasse a faceta estética-artística. Considera limitado, também, seu interesse pela persuasão, fim prático da retórica. 
D. Russell, em Criticism in Antiquity, ${ }^{3}$ de 1981, toma DH por um "professor, essencialmente", cuja "doutrina estilistica" é marcada pelo mecanicismo e por bases mal fundamentadas (Russell, 1981, p. 54). Como Atkins e outros, atribui-lhe uma "atitude escolástica" (id., 1981, p. 51) em seus tratados, muito embora elogie sua sensibilidade, seu vocabulário, sua competência como professor de retórica - avaliação, no mínimo, curiosa -, sua proximidade com as idéias modernas, a espécie de close reading que faz dos textos, ${ }^{4}$ e afirma: "He excels in close observation and the analysis of stylistic effects." (id., 1981, p. 53). Ao fim, Russell compara DH a 'Longino', e conclui que o primeiro é menos atraente porque mais técnico. ${ }^{5}$

Em The Cambridge History of Classical Literature I-Greek Literature, editado em 1985 por Easterling e Knox, G. W. Bowersock, no breve capítulo "The Literature of the Empire", refere-se a DH como um crítico literário digno de atenção e como um rhetor bem intencionado, todavia incapaz de escapar à frieza da retórica tradicional.

Data do mesmo ano a edição Loeb Dionysius of Halicarnassus - The Critical Essays II, de S. Usher, o qual, na introdução ao tratado, pinta DH como um professor erudito de gosto apurado, apaixonado por seu métier, mas, inegavelmente, um produto da tradição retórica, sempre prático e não raro superficial e apressado.

Em 1989, M. Heath publica Unity in Greek Poetics, no qual enfatiza que DH manteve, mesmo em tratados de historiografia, um olhar crítico retórico (cf. Heath, 1989, p. 91). Assim também o vê V. Botas, em Dionisio de Halicarnaso, de 1992.

G. Kennedy, em 1997, publica The Cambridge History of Literary Criticism Classical Criticism, no qual atribui a DH - crítico maior, seguido de Horácio, na era de Augusto $^{6}$ - sensibilidade e percepção aguçadas, salientando a importância de seus estudos sobre a prosa, novidade entre os antigos - "(...) Dionysius may be the first critic to offer detailed scansion of lenghty passages of prose." (Kennedy, 1997, p. 241). Igualmente elogia sua consciência metodológica e o close reading que $\mathrm{DH}$ faz dos textos que cita.

Todas as visões até aqui listadas - unânimes em reconhecer a relevância dos estudos sobre a prosa que fez $\mathrm{DH}$, o valioso close reading em suas análises, seu método comparativista e o rico e apropriado vocabulário que constrói -, repetem um perfil semelhante: DH era técnico, mas sensível; retórico, mas nem sempre tradicional; frio, mas apaixonado; ora profundo e meticuloso em suas análises, ora superficial e descuidado; e assim por diante. Bastam esses pólos opostos - aliás, tão caros ao pensamento grego - para notar a oscilação pendular na avaliação de DH.

Se tal oscilação é saudável - dizia Nelson Rodrigues, numa de suas frases de impacto, que "Toda unanimidade é burra" -, ela é também curiosa. O que encobrirá? 


\section{- quadro dos comentários sobre o De compostione uerborum:}

Introduziu este trabalho a fala entusiasmada de Racine recomendando a Boileau a leitura do De comp.. Em certo momento, aconselhando seu destinário quanto ao emprego de palavras "nobres" ou "baixas", Racine lembra uma passagem no tratado de DH sobre o mesmo assunto, e pede: "Prenez la peine de lire toute la réflexion de Denys d'Halicarnasse, qui m'a paru très belle et merveilleusement exprimée (...)” (p. 518. cf. n. 1). Racine encontrou no De comp. valor, beleza, e força expressiva.

Egger, no capítulo "Sur l'arrangement des mots" de Denys d'Halicarnasse, afirma: "Le traité (...) est même de première importance pour l'étude du style oratoire." (Egger, 1902, p. 67). Após criticar as bases incertas do tratado - defeito apontado por muitos -, emenda: "(...) mais avec hi $[\mathrm{DH}]$ on voit jusqu'où allait la finesse d'un Grec dans l'étude musicale de sa langue et en particulier de l'ordre des mots." (id., 1902, p. 68).

Quanto ao método de $\mathrm{DH}$, as conclusões de Egger serão recorrentes: a preocupação com o arranjo das palavras - súnthesis ( $\sigma u ́ v \theta \varepsilon \sigma ı \zeta)$ ou compositio - em detrimento do conteúdo que expressam; o empréstimo à música de ferramentas para avaliação da composição das palavras; a eventual falta de clareza; a ordenação sistemática de noções espalhadas nas obras de seus antecessores. Por fim, diz: "Nous n'avons pas ici le brillant exposé d'un esprit large et d'un écrivain lumineux, mais il faut reconnaitre combien cette oeuvre, même imparfaite, nous apporte de renseignements utiles et de vues intéressantes." (id., 1902, p. 111).

No segundo volume de Literary Criticism in Antiquity, em "Classicism and Prose Style: Dionysios of Halicarnassus", Atkins afirma que encontramos de modo mais claro e sistemático o pensamento de $\mathrm{DH}$ no De comp., cujo assunto - a $\sigma u ́ v \theta \varepsilon \sigma i \varsigma$ (súnthesis) ou compositio - é parte integrante da formação retórica sobre a elocutio ou $\lambda \hat{\varepsilon} \xi i \varsigma$ (léxis).

Kennedy, em The Art of Persuasion in Greece, aponta duas características comuns aos tratados retóricos de $\mathrm{DH}$ - dentre os quais, o De comp. - quando os compara às produções do século IV a.C. ateniense: "(...) tendency toward monographic studies"; "increasing concern of rhetoric with all literature, not just with oratory." (Kennedy, 1963, p. 268). Esses traços, conclui, espelham o papel protagonista da retórica na educação.

Grube, no seu The Greek and Roman Critics, ressalta o comparativismo crítico empregado por $\mathrm{DH}$ no tratado, bem como a farta exemplificação, freqüentemente alvo de close reading. Ao fim, afirma que o De comp. - uma "obra-prima" (Grube, 1965, p. 217) -, ao abordar um aspecto da elocutio, é um estudo de teoria literária, e não de crítica. $^{7}$ 
Stanford, em The Sound of Greek, enfatiza a minuciosidade analítica de DH; no capítulo "Theoretical Aspects of Euphony", escreve: "The fullest ancient Greek discussion of euphony now extant is that in the treatise on the arragement of words by Dionysius. Its basic principles go back to at least the fifth century." (Stanford, 1967, p. 51).

Kennedy, na obra The Art of Rhetoric in the Roman World, observa que no De comp. a elocutio é a única preocupação, a despeito das palavras de abertura de $\mathrm{DH}$ afirmando que a composição é estudo obrigatório para aqueles que desejam praticar a oratória. $\mathrm{O}$ autor ainda ressalta: "Dionysius' work is of considerable significance in the history of criticism, particularly because of his development of a comparative method, his experiments with rewriting passages to illustrate the effects of composition, and his evaluations of authenticity." (Kennedy, 1972, p. 344).

Russell, em Criticism in Antiquity, refere-se ao De comp. como a mais original e menos retórica das obras de $\mathrm{DH}$, pois haveria lá rejeição às explicações gramaticais e lógicas. Assinala, ainda, que para entendermos DH e seus contemporâneos, é necessário ter em mente que a persuasão era o objetivo tanto dos oradores quanto dos poetas.

Bowersock, em seu ensaio "The Literature of the Empire", atenta para um recurso, já marcado por Kennedy em The Art of Rhetoric in the Roman World, do qual se vale $\mathrm{DH}$ em seu tratado como método para provar o que afirma: "(...) his illuminating device of recasting sentences (...)" (Easterling e Knox, 1985, p. 644). Para o autor, a leitura do tratado é difícil, mas gratificante.

Usher, na edição Loeb do De comp., diz que o tratado é sobre a técnica e a crítica literárias, porém é limitado por seu próprio assunto. Usher elogia um recurso metodológico que muitos ressaltam: DH toma sentenças originais de Heródoto, por exemplo, e as reescreve de modo diverso para mostrar que, sendo a língua grega livre de regras de ordem das palavras na frase, o discernimento e o gosto do autor são decisivos na compositio, e devem, portanto, ser cultivados e refinados constantemente.

Quanto à análise feita por DH daquilo que cita, Usher discorda de um consenso: "He $[\mathrm{DH}]$ introduces his readers to the subject with a different number of examples, not analysing them in detail", negativa que contraria a avaliação da maioria dos estudiosos aqui mencionados, "and yet establishing confidence in the mastery of the classical authors who are to be his models throughout the treatise." (Usher, 1985, p. 6). Somam-se a essa crítica outras predominantemente negativas, decorrentes do que Usher conclui faltar no tratado e de expectativas não correspondidas por $\mathrm{DH}$ - critérios decerto embaraçosos, que infelizmente se repetem noutras obras. Porém, Usher termina "salvando" o tratado: "In spite of its self-imposed limitations, its inconsistencies and ambiguities, it cannot 
be read without enriching the experience and sharpening the critical perception of anyone with a feeling for the power of the written or spoken word." (id., 1985, p.12).

V. Botas classifica o De comp. como obra retórica que é um "Pilar de la teoría de la prosa artística de todos los tiempos." (Botas, 1992, p. 14). Para ele, DH aperfeiçoou um "nuevo método de análisis retórico: el fonoestilístico (...)" (id., 1992, p. 21).

Kennedy, em The Cambridge History of Literary Criticism, afirma ser o De comp. um trabalho de teoria crítica de perfil tradicional, e destaca o método do comparativismo crítico empregado por $\mathrm{DH}$.

Depreende-se desse "apanhado" de visões que o De comp. é reconhecidamente importante, sobretudo pelo método analítico de $\mathrm{DH}$ - o comparativismo e a reescritura de passagens -, por sua contribuição aos estudos de prosa e fonética gregas, pela citação farta e pela análise dos exemplos.

Contudo, longe de irrepreensível, o tratado é alvo de críticas e cobranças não raro incoerentes com sua especificidade. Voltando ao painel anterior, nota-se que o mesmo se dá em relação a $\mathrm{DH}$, avaliado muitas vezes por padrões demasiado atuais. Provavelmente é essa uma das razões que explicam a oscilação crítica quanto a DH e seu De comp., ambos fontes de entusiasmo e frustração.

\section{Retórica e literatura}

Cabe, agora, considerar a retórica e a literatura, uma vez que as referências a $\mathrm{DH}$ e seu tratado valem-se de adjetivos delas derivados. Os estudiosos já mencionados ora chamam DH um rhetor, ora crítico literário, ora teórico da literatura; o De comp. é ora retórico, ora obra de teoria literária, ora, ainda, de crítica. É preciso, pois, voltar aos mesmos críticos, e até recorrer a outros, para problematizar o uso de certos rótulos.

\section{- algumas palavras sobre a retórica à época de Dionísio de Halicarnasso:}

As obras referidas, ao falarem da época de $\mathrm{DH}$ - a era romana de Augusto -, enfatizam dois pontos: 1) o lugar privilegiado ocupado pela elocutio ou léxis ( $\lambda \dot{\varepsilon} \xi$ is) na retórica; ${ }^{8}$ 2) a controvérsia "aticismo" x "asianismo". DH, homem de seu tempo, envolveu-se na defesa do "aticismo" e na definição dos modelos clássicos a serem adotados, e priorizou, mesmo em seus trabalhos historiográficos, o estudo da elocutio.

Egger, por exemplo, comenta, ao mencionar 'Longino': “Comme Denys, c'est un attique intraitable (...)” (Egger, 1902, p. 10). Noutro momento, chama DH "o apóstolo” 
(id., 1902, p. 72) do "aticismo"/“classicismo", e e alerta: "On n'oubliera pas non plus qu'il [DH] a pour but de réagir contre l'eloquence asiatique (...)" (id., 1902, p. 111). Para o estudioso, a defesa do "aticismo" e o estabelecimento dos modelos clássicos são os grandes méritos de DH: "(...) son véritable mérite, l'admiration profonde et comunicative pour les auteurs classiques (...)” (id., 1902, p. 238).

O que foram o "aticismo" e o "asianismo"?

Segundo os estudiosos, trata-se de uma polêmica latente na Roma do século I a.C., que consiste na discussão dos modelos e métodos a serem seguidos pela retórica - os ideais clássicos ("aticismo"), ou os da época helenística, dos alexandrinos ("asianismo"). Encarnava esse modelo a figura de Hegesias, cuja elocutio caracterizavase pelo excesso de ornamentos e artifícios, por certa frivolidade - para alguns, efeminada -, e pelo distanciamento da vida real. Em contraposição, o "aticismo" pautava-se pela simplicidade, seriedade, precisão, e despojamento de adornos; seu ideal era a elocutio dos antigos gregos, com destaque para os oradores áticos.

Para Atkins, Cícero é a grande mola que impulsiona, em Roma, o restabelecimento do modelo ático. ${ }^{10}$ Em sua esteira, entre os romanos da época de Augusto, cita Horácio e sua Ars Poetica, uma das poucas exceções de crítica literária feita por um poeta, pois "(...) literary judgement was mainly in the hands of the grammatici, who as the professional teachers were the recognised critics (...)" (Atkins, 1952, p. 92). Na mesma época, destaca-se outro nome que se empenhou no resgate dos modelos clássicos: DH, cujo objetivo último "(...) was, broadly speaking, a continuation of Cicero's purpose, the establishment of correct standards and methods in oratory and prose style." (id., 1952, p. 111).

Elocutio: essa é a dimensão da retórica que preenche o cenário da Roma de Augusto - aliás, um pouco antes, desde Cícero, e por muito tempo depois, com Quintiliano e outros. Portanto, além de alvo de disputas no que tange à adoção deste ou daquele padrão, a arte retórica é a arte da elocutio. Russell traduz, como é corrente, elocutio ou léxis por "estilo" - signo para nós bastante carregado de sentidos vários -, e afirma sobre a "teoria estilística" desenvolvida naquela época: "Stylistic theory was of course of general literary concern and dealt with poets as well as with prose-writers; but it is important to remember that its origins were rhetorical, and its purposes primarily normative rather than descriptive." (Russell, 1981, p. 129).

Egger alerta: "N'oublions pas que Denys parle ici [De comp.] d'art oratoire, de prononciation déclamée, de lecture." (Egger, 1902, p. 90). DH, no De comp., preocupa-se fundamentalmente em forjar uma teoria da elocutio a partir de modelos clássicos: o contexto reflete-se no próprio texto. Por que então exigir do tratado, um produto de 
sua época, aquilo que se exige hoje de um crítico literário? A pergunta se repete, mas parece indagar seu próprio sentido.

\section{- breves linhas sobre a retórica e a literatura:}

Veja-se a definição de "retórica" em The Concise Oxford Dictionary of Literary Terms: "(...) the deliberate exploitation of eloquence for the most persuasive effect in public speaking or in writing. It was cultivated as an important art and science in antiquity, and was an essential element of medieval university education, involving the elaborate categorizing of figures of speech together with the arts of memory, arrangement, and oratorical delivery. The emphasis on sincerity in the culture of Romanticism helped to discredit rhetoric, so that the usual modern sense of the term implies empty and ineffectual grandness in public speech. Modern critics sometimes refer to the rhetorical dimension of a literary work, meaning those aspects of the work that persuade or otherwise guide the responses of the readers." (Baldick, 1991, p. 188-9).

No verbete do dicionário temos a síntese do que seria um dos resultados do privilégio da elocutio em detrimento das outras partes da retórica, a partir do século I a.C. em diante. Poder-se-ia acrescentar às poucas causas listadas no verbete a influência de determinada leitura de Platão, com seu "horror" aos sofistas. A hostilidade ganha espaço no século XIX, e a retórica passa a carregar em seus ombros enfraquecidos uma pesada carga pejorativa. Hoje, após muitas revisões, a retórica foi recuperada, mas em parte; revendo tudo o que foi dito até aqui, nota-se na crítica aos antigos um tom constante de antipatia e desagrado implícita em termos como "técnico", "frio", "retórica tradicional", "persuasão", "prática”.

Afirma Kennedy: "Rhetoric, defined in the strictest sense, is the art of persuasion as practiced by orators and described by theorists and teachers of speech. That basic meaning may be extented, however, to include the art of all who aim at some kind of attitude change on the part of their audience or readers, and then applied to what I shall call secondary rhetoric: critical or aesthetic theory not directly concerned with persuasion and the technique of works produced under the influence of these critical concepts." (Kennedy, 1972, p. 3). Nesse parágrafo, Kennedy aproxima, em sua definição, a retórica da poesia, marcando como ponto comum o objetivo de ambas de afetar, sensibilizar seus ouvintes ou leitores. Tal idéia é bastante recorrente entre os críticos.

Russell, assim como outros estudiosos, aponta para as dificuldades de delimitar as fronteiras da retórica. Estendendo-se por toda a literatura sob pretexto de ensinar a persuasão, a retórica teria gerado um tipo de leitura e análise sempre muito prático. ${ }^{11}$ Enfatiza o crítico: "In the end, therefore, the rhetors took all literature as their province, and encouraged the kind of analysis and criticism that suited their purpose. This was to the detriment 
of aesthetic judgement, and more or less blocked the way to a historical view of literature." (Russell, 1981, p. 117). ${ }^{12}$ Para os antigos, a arte retórica era toda a arte de expressão, incluindo a prosa; a expressão "all literature", recorrente na crítica, inclui lírica, épica, tragédia, comédia, história, orações, e assim por diante. O que aparece como reclamação é simplesmente um dado contextual. Vale lembrar que o conceito de literatura nem sempre esteve presente e, mesmo quando esteve, nunca foi único: cada momento histórico forjou o seu conceito, e em certos momentos, como ocorre hoje, vários conceitos coexistiram.

DH discerne gêneros de discurso (elocutio ou léxis), pois chama Safo de melopoiôn ( $\mu \varepsilon \lambda$ o $\pi$ oi $\omega \hat{\nu}$ - o verbo melopoiéo significa "fazer poemas líricos, compor músicas, es-

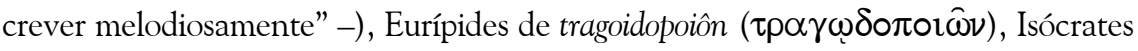
de rhetóron ( $\rho \eta \tau o ́ \rho \omega \nu)$. Entretanto, considera-os todos exemplos úteis para a ilustração de seus pontos de vista - Heródoto, um historiador, e Homero, poeta épico, são as figuras mais citadas no De comp.

Diz o verbete "literatura" do The Concise Oxford Dictionary of Literary Terms: "(...) a body of written works related by subject-matter (...), by language or place of origin (...), or by prevailing cultural standards of merit. In the last sense, 'literature' is taken to include oral, dramatic, and broadcast compositions that may not have been published in written form but which have been (or deserve to be) preserved. Since the $19^{\text {th }}$ century, the broader sense of literature as a totality of written or printed works has given way to more exclusive definitions based on criteria of imaginative, creative, or artistic value, usually related to a work's absence of factual or practical reference (...). Even more restricted has been the academic concentration upon poetry, drama, and fiction. Until the mid-20 th century, many kinds of non-fictional writing - in philosophy, history, biography, criticism, topography, science, and politics - were counted as literature; implicit in this broader usage is a definition of literature as that body of works which - for whatever reason - deserves to be preserved as part of the current reproduction of meanings within a given culture (...)" (Baldick, 1991, p. 124).

Mostra bem o texto do verbete que definir o que é literatura nunca foi tarefa fácil. Wellek, em Teoria da Literatura, editado em inglês no ano de 1949, discorre sobre as várias possibilidades de entendermos o termo "literatura". ${ }^{13}$ Se para nós é tão árdua empreitada chegar a uma única definição, como cobrá-la dos antigos, os quais sequer a entendiam como nós? Fala-se de sua incompetência ou incapacidade em fazer análise, crítica, teoria, e história literárias; um detalhe é esquecido ou ignorado - a literatura é uma instituição moderna, que começa a se especializar e a definir seu objeto e campo de atuação a partir do século XVIII. ${ }^{14}$ 
Parece que é essa a chave para entendermos o entusiasmo e o desapontamento dos críticos diante de tratados como o De comp., de $\mathrm{DH}$, que, obviamente, não tinha, nem poderia ter, as preocupações de um crítico literário moderno. É preciso, pois, ter cuidado ao empregar conceitos hoje fundamentais, tais como originalidade, criatividade, autoria e interpretação, quando se trata dos antigos. A maioria dos estudiosos não tem esse cuidado, ou padece de lapsos, o que compromete, não com pouca freqüência, suas considerações.

Há uma inadequação, quase uma impropriedade, em chamar DH um crítico literário, cobrando-lhe originalidade, fundamentação teórica, análises mais complexas e interpretação dos textos que cita - e ele cita, em "pé de igualdade", é preciso insistir, oradores, poetas, prosadores, historiadores, ciente de sua especificidade, mas tomando tudo como "discurso" ou elocutio. Certa linha atual de estudos literários, os "cultural and gender studies", chega a cobrar dos antigos posicionamentos pautados por questões dos séculos XIX e XX, sobretudo, como o feminismo e o homossexualismo.

Se não podemos pensar como os gregos e romanos, temos, ao menos, que manter certo distanciamento de conceitos e categorias já em nós introjetados. Em raros momentos luminosos, a crítica é bem sucedida nesse esforço; nascem deles as páginas mais sensíveis dos estudos clássicos.

\section{O tratado De compostione nerborum}

Resta, pois, ler o De comp., de DH, para ilustrar, como ele mesmo fazia, parte do que se disse até aqui. A matéria do tratado é extensa; serão abordados os pontos relevantes para a discussão em curso, bem como alguns problemas de tradução.

\section{- o título do tratado:}

Perì sunthéseos onomáton (ПEPI $\Sigma \mathrm{YN} \Theta \mathrm{E} \Sigma \mathrm{E} \Omega \Sigma$ ONOMAT $\Omega \mathrm{N}$ ) é o título original em grego; a edição Loeb, de Usher, o traduz, livremente, por On Literary Composition, ao contrário do que faz boa parte da crítica, que o traduz literalmente por On the Arrangement of Words.

Aparentemente inofensiva, a tradução de Usher sugere uma determinada leitura intimamente relacionada à postura que se adota frente a um trabalho de crítica literária: teoricamente, ler-se-á um estudo sobre a literatura escrita que trará análises 
fundamentadas e profundas dos textos sobre os quais se debruça, objetivando sua avaliação. Não é isso que encontraremos no tratado de DH.

O mesmo tipo de tradução/interpretação ocorre, por exemplo, noutra edição Loeb: Plutarch's Moralia I, de F. C. Babbitt. O título do tratado Pos dei tòn vèon poiemáton akoúein ( $\Omega \Sigma \Delta$ EI TON NEON ПOIHMAT $\Omega N$ AKOYEIN) é traduzido/ interpretado How the Young Man Should Study Poetry, desprezando o significado do

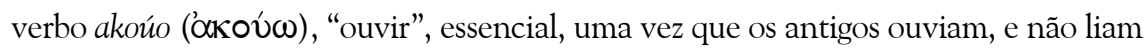
como nós o fazemos. Diz Stanford: "In ancient Greece and Rome reading without speaking the words seems to have been a rare accomplishment, and it remained so until well into the Middle Ages." (Stanford, 1967, p. 1).

No caso do De compostione uerborum - título latino, mais literal, mantido por edições mais cuidadosas -, a interpretação na tradução confere à expressão sunthéseos onomáton (composição e arranjo de palavras, de nomes), uma carga significativa que lá não está originalmente. DH falará não de "composição literária", mas de composição de um discurso diverso da fala comum, um discurso que possui uma forma e ordenação próprias.

A tradução de Usher acima citada reflete menos o sentido dos termos do título do De comp. e mais as expectativas do próprio tradutor.

\section{- apresentação do tratado:}

Seguindo uma tradição dos tratados de retórica, o De comp. é endereçado a alguém; neste caso, Rufo Metílio é o destinatário, e diz DH ao pupilo: "Celebras teu primeiro aniversário desde que atingiste a idade adulta (...) Envio-te, pois, o produto e filho de meu aprendizado e de meu espírito, que te será, ao mesmo tempo, um bem e uma ferramenta útil para todas as coisas da vida que acontecem através do discurso; a mais necessária dentre todas as ferramentas para todos aqueles, igualmente, que praticam a oratória (...) mas sobretudo para jovens como tu, que estão iniciando seus estudos (...)" (De comp. 1, p. 14). ${ }^{15}$

O objetivo de DH é oferecer a seu aluno um tratado que lhe seja útil em sua formação como orador; mais que isso, DH deseja que seu trabalho seja útil - tenha uma função prática de educação - sobretudo $\left(\mu \alpha^{\prime} \lambda \iota \tau \tau \alpha\right)$ aos jovens, o que se pode entender como preocupação didática do professor. Na introdução ao tratado, Usher (1985) bem lembra, à semelhança de outros estudiosos, que o ensino de retórica, entre os antigos, está intrinsecamente associado à produção do aluno. Daí a minuciosidade das explicações, o detalhamento, o tom prático, a farta exemplificação, e o aspecto prescritivo ou normativo de tratados como o De comp. 
Portanto, o objetivo de DH é diverso dos objetivos de um trabalho de crítica literária; também o serão os procedimentos e os resultados.

\section{- assunto do tratado:}

Como diz o título, DH tratará do arranjo das palavras em discursos que possuem forma específica - a épica, a lírica, a história, a oração, entre outros-, pois, para ele, a composição é o aspecto mais importante da elocutio, e o orador deve dominá-lo se quiser ser bem sucedido.

A fim de provar sua certeza, DH cita uma passagem de Homero e outra de Heródoto, e as reescreve alterando o arranjo das palavras - método reconhecido pelos críticos como ponto forte do tratado. Sua conclusão é: “(...) a persuasão († $\pi \varepsilon 1 \theta \omega) d a$ elocutio não reside na beleza das palauras, mas na sua combinação." (De comp., 3, p. 32). A mesma passagem é assim traduzida por Usher: "(...) the appealing quality of his style is derived, after all, not from the beauty of the words but from their combination." (Usher, 1985, p. 33).

O que pode parecer mera diferença é antes uma tentativa de "suavizar" termos como persuasão, diretamente ligados à retórica. Tal tentativa ultrapassa a tradução; se retomarmos as visões sobre $\mathrm{DH}$ e o tratado aqui mencionadas, verificaremos que a crítica tenta o mesmo, exaltando em Dionísio aquilo que não é próprio do rhetor e da retórica.

Apesar de contraditório, os críticos que tentam afastar DH da retórica e aproximá-lo da crítica literária alertam, às vezes, que para enterdermos $\mathrm{DH}$ e seus contemporâneos, é necessário ter em mente que a persuasão era o objetivo tanto dos oradores quanto dos poetas (cf. Russell, 1981, p. 171). Kennedy, em The Art of Persuasion in Greece, ressalta: "Elegiac and lyric poems were occasionally composed in the form of addresses designed to persuade - Callinus to his countrymen and Sappho to Aphrodite are examples." (Kennedy, 1963, p. 6).

\section{- crítica ao "asianismo":}

Como já se disse, $\mathrm{DH}$ adotou, como modelos clássicos, os oradores áticos. Ao longo do De comp., Isócrates, Demóstenes e outros são constantemente citados. Forjando e defendendo o "aticismo", DH não poupa o "asianismo" e Hegesias, sua encarnação: "Esta forma de composição preciosa, degenerada, efeminada, étípica de Hegesias." (De comp., 4, p. 40. Cf. De comp., 18, p.140-2.). 


\section{- a composição e o som:}

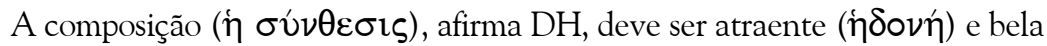
( $\kappa \alpha \lambda \lambda \eta ́)$. Para tanto, é preciso observar uma série de detalhes - desde as vogais até os períodos - que, juntos, compõem o discurso; mas isso não basta. Quatro princípios devem ser igualmente considerados: a melodia (o $\mu \dot{\varepsilon} \lambda \circ \varsigma$ ), o ritmo (ó ṕv̂ $\theta \mu \varsigma$ ), a

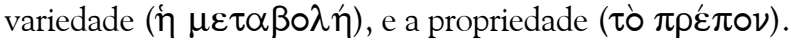

Longamente $\mathrm{DH}$ discorre sobre cada um dos componentes do discurso e as possibilidades de combinações entre eles, pautado tão somente pelos quatro princípios e pelo som que cada vogal, cada combinação, cada componente, enfim, produz.

Dentre os princípios da composição, dois ligam-se diretamente à música; a própria palavra composição ( $\sigma \hat{v} \nu \theta \varepsilon \sigma i \varsigma)$ tem muitos sinônimos no tratado, sendo um

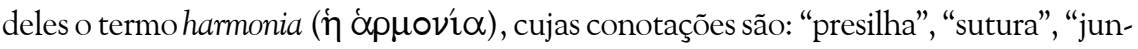
ção", "escala musical", "música", "arranjo determinado de palavras, pronto a ser ajustado à música", "concórdia", "união". ${ }^{16}$ Vale salientar, ainda, o vocabulário metafórico sinestésico predominantemente associado à audição - o paladar é o segundo sentido mais referido -, e o emprego freqüente de conclusões norteadas por nada mais além da

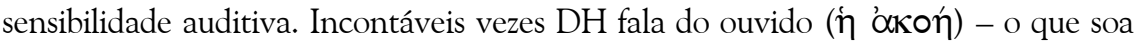
agradável, o que desagrada.

Essa breve observação do vocabulário já aponta para uma dimensão fundamental do tratado que é, não raro, menosprezada, chamada de ilógica, acusada de inconsistente: a eufonia ( $\grave{\eta} \varepsilon \dot{v} \phi \omega \nu i \alpha)$.

O estudo de Stanford, The Sound of Greek, sublinha a importância do som na literatura grega - sua própria essência. O próprio DH diz: "Na léxis, como na música, as frases têm melodia, ritmo, variedade e propriedade, de modo que aqui também o ouvido se deleita com as melodias, é agitado pelos ritmos, recebe bem as variações, e deseja, sobretudo, o que é apropriado. A distinção [entre música e elocutio] é simplesmente uma distinção de grau." (De comp. 11, p. 76). Tal observação leva a outra de Stanford: "While rhetoricians had to remind their matter-of-fact pupils that oratory and music were sisters, writers on poetry hardly needed to emphasize the kinship." (Stanford, 1967, p. 27). E completa o crítico, sobre os antigos: "Artistic language, as they saw it, was a kind of music." (id., 1967, p. 28).

Nada para um grego cala mais fundo e produz tanta impressão, lembram $\mathrm{DH}$ e Stanford, do que o som que agrada aos ouvidos por sua beleza, atratividade, e encanto.

\section{- as três formas da composição:}

Buscando filiar DH a outros pensadores, os estudiosos o aproximam de Cícero e Quintiliano, pois os três teriam desenvolvido uma teoria da elocutio 
tripartida. De fato, no De comp. são três as formas de composição: a "austera"

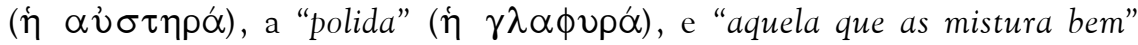

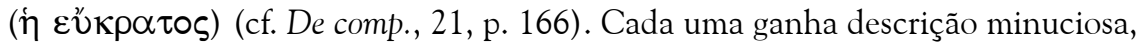
além de vasta exemplificação, e é exatamente por um certo exemplo da compositio "polida" que o tratado se celebrizou.

Em De comp., 23 (p. 196-198), DH cita, integralmente, o famoso fragmento 1 (Fr.1) de Safo, conhecido como "Hino a Afrodite"; desse modo, o tratado de Dionísio, tendo sobrevivido, conservou o poema e propiciou sua transmissão indireta até nós. Sedentos, os estudiosos ressaltam os comentários elogiosos de $\mathrm{DH}$, mas o acusam de superficialidade e brevidade, uma vez que Dionísio só diz o quanto basta para seu intuito - ilustrar um tipo de composição -, e, para a frustração de muitos, não interpreta, como faríamos, tão belo poema. Porém, esses críticos se esquecem que os antigos não fariam isso, mas somente ouviriam e perceberiam a adequação da forma ao gênero do discurso apresentado publicamente.

Que encerrem, pois, este texto, as palavras do próprio $\mathrm{DH}$ sobre o poema de Safo - a percepção de um antigo diante de um discurso lírico: "A eufonia

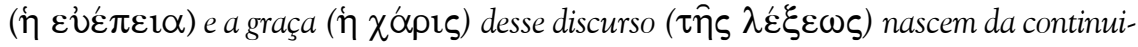
dade e suavidade da composição ( $\tau \hat{\omega} \nu$ óp $\mu$ ovi $\hat{\omega} \nu)$, pois as palavras jazem umas ao lado das outras e são costuradas juntas segundo algumas afinidades e combinações naturais das letras. Por quase toda a ode, juntam-se às consoantes mudas somente aquelas vogais que são naturalmente colocadas antes ou depois umas das outras quando pronunciadas juntas numa única sílaba. Poucas são as coincidências de semivogais ou consoantes mudas, ou dessas últimas e vogais que perturbem o fluxo da voz. Eu, quando examino ( $\alpha \nu \alpha \sigma \kappa о \pi \circ u ́ \mu \varepsilon v o \varsigma)$ a ode em sua totalidade, descubro que, em todos aqueles substantivos e verbos e outras partes do discurso, há somente cinco, ou seis, talvez, combinações de semivogais e consoantes mudas que não se misturam naturalmente. Mas essas combinações em nada prejudicam a qualidade musical sem par da linguagem. Quanto às justaposições das vogais, as ocorrências são ainda mais raras, e das sentenças umas às outras são

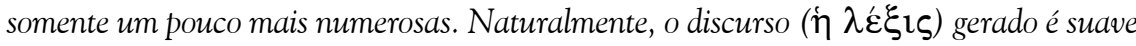
e fluente, musical, porque o arranjo das palavras não causa nenhuma turbulência nas suaves ondas sonoras que dele se desprendem" (De comp., 23, p. 198-200).

\section{Notas}

* Mestranda em Grego do Programa de Pós-Graduação em Letras Clássicas da FFLCH/ USP (bolsista da Fapesp).

1 Lettre à Boileau XXV. In: Oeuvres Complètes, 1962, p. 518-9. 
2 A obra foi republicada em 1952, e é essa a edição usada nas citações.

3 Cf. crítica em Verdenius, 1983, p. 15, nota 2. À p. 14, Verdenius critica também a obra de Atkins citada.

4 O termo usado por Russell e outros estudiosos é "close analysis". Por questões de tradução, prefiro usar a já consagrada expressão close reading.

5 Tal comparação e conclusão são recorrentes. Cf. Atkins, Grube, Russell \& Winterbottom, entre outros.

6 Trata-se de opinião comum. Cf. do mesmo autor The Art of Rhetoric in the Roman World.

7 Algumas vezes Grube se refere a DH como um "literary theorist". Cf. 1965, p. 230.

8 Cf. Kennedy, 1972, p. 363: "Rhetoric has ceased to be concerned primarily with persuasion and reveals itself as an art of expression."

9 Cf. Kennedy, 1972, p. 354: "In Dionysius' plans to encourage the further development of the Attic style the dominant feature is classicism, the study and imitation of the classical Greek writers and most of all the Attic orators".

10 Cf. vol.II, p. 15-46. À p. 104, lê-se sobre Cícero: "Basing his theories mainly on Aristotle and Isocrates, he had endeavoured to establish in oratory the traditions and methods of classical Greece; and while condemning alike the florid Asianism and the narrow Atticism tendencies then current, he had set before his generation a finer and a more complete conception of the nature of oratory."

11 Russell, 1981, p. 171: "We cannot understand Dionysius or 'Longinus' without both thinking of the rhetorical study of style and of 'invention' and being prepared to read the poets as though they too, like the orators, aimed to 'persuade'.".

12 Tal idéia já se encontra em texto anterior de Russell, "Rhetoric and Criticism", 1967.

13 Cf. especialmente o capítulo II, "Natureza da Literatura".

14 Cf. “Teoria da Literatura”, de Souza, 1992, e Dupont, 1994, p. 17, onde lê-se: “(...) l'invention littéraire est relativement récente dans notre propre histoire et rien ne permet d'affirmer a priori qu'elle existât aussi du temps de Thucydide ou Mécène.".

15 A numeração de páginas corresponde à edição Loeb do texto grego feita por Usher, 1985. As traduções do grego para o português foram feitas por mim.

16 Cf. Corrêa, Harmonia: mito e música na Grécia Antiga.

\section{REFERÊNCIAS BIBLIOGRÁFICAS}

ATKINS, J. W. H. Literary Criticism in Antiquity: a sketch of its development. Vol. I. Greek. London: Methuen \& Co., 1952.

. Literary Criticism in Antiquity: a sketch of its development. Vol.II - Graeco-Roman.

London: Methuen \& Co., 1952. 
BABBITT, F. C. Plutarch. Moralia in sixteen volumes. I, 1A-86A. Cambridge: Harvard University Press, 1986. (The Loeb Classical Library).

BALDICK, C. The Concise Oxford Dictionary of Literary Terms. Oxford: Oxford University Press, 1991.

BOTAS, V. B. Dionisio de Halicarnaso: tres ensayos de crítica literaria. Madrid: Alianza Editorial, 1992.

BOWERSOCK, G. W. "The Literature of the Empire". In: EASTERLING, P. E.; KNOX, B. W. (eds.). The Cambridge History of Classical Literature: Greek Literature - I. Cambridge: Cambridge University Press, 1985. P. 642-5.

BOWRA, C. M. Greek Lyric Poetry: from Alcman to Simonides. $2^{\text {nd }}$ ed. Oxford: Clarendon Press, 1961.

CORRÊA, P. C. Harmonia: mito e música na Grécia Antiga. Tradução do original: Harmoniai and nomoi. MA in Classical Studies, RHBNC, University of London, 1987.

DUPONT, F. L'Invention de la Littérature: de l'ivresse grecque au livre latin. Paris: La Découverte, 1994.

EGGER, M. Denys D'Halicarnasse: essai sur la critique littéraire et la rhétorique chez les grecs au siècle d'Auguste. Paris: Alphonse Picard et Fils, Éditeurs, 1902.

GRUBE, G. M. A. The Greek and Roman Critics. London: Methuen \& Co., 1965.

HEATH, M. Unity in Greek Poetics. Oxford: Clarendon Press, 1989.

KENNEDY, G. The Art of Persuasion in Greece. London: Routledge / Kegan Paul, 1963. . The Art of Rhetoric in the Roman World. 300BC-AD300. Princeton: Princeton University Press, 1972.

. The Cambridge History of Literary Criticism-I. Classical Criticism. Cambridge: Cambridge University Press, 1997.

LIDELL, SCOTT \& Jones. Greek-English Lexicon with a Revised Supplement. $9^{\text {th }}$ ed. Oxford: Clarendon Press, 1996.

MEYER, M. "Introdução". In: Questões de Retórica: Linguagem, Razão e Sedução. Tradução de António Hall. Lisboa: Edições 70, 1998.

NICOSIA, S. Tradizione Testuale Diretta e Indiretta dei Poeti di Lesbo. Roma: Edizioni dell'Ateneo, 1976.

RACINE. Oeuvres Complètes. Paris: Editions du Seuil, 1962.

RUSSELL, D. A. Criticism in Antiquity. London: Duckworth, 1981.

. Rhetoric and Criticism. Greece and Rome. Oxford, v. 14.2, p. 130-144, 1967. 
; WINTERBOTTOM, M. Classical Literary Criticism. Oxford: Oxford University Press, 1989.

SOUZA, R. A. de. Teoria da Literatura. In: JOBIM, J. L. (Org.). Palavras da Crítica: tendências e conceitos no estudo da literatura. Rio de Janeiro: Imago, 1992.

STANFORD, W. B. The Sound of Greek. Studies in the Greek Theory and Practice of Euphony. Berkeley: University of California Press, 1967.

USHER, S. Dionysius of Halicarnassus - The Critical Essays II. Cambridge: Harvard University Press, 1985. (The Loeb Classical Library).

VERDENIUS, W. J. The Principles of Greek Literary Criticism. Mnemosyne. Leiden, v. 36, p. 14-59, 1983.

WELLEK, R.; WarRen, A. Teoria da Literatura. Tradução de José Palla e Carmo. Lisboa: Publicações Europa-América, 1962.

WIMSATT, W. K.; Brooks, C. Crítica Literária. Breve História. Tradução de Ivette Centeno e Armando de Morais. Lisboa: Fundação Calouste Gulbenkian, 1971.

RAGUSA, Giuliana. De compositione uerborum: notes for a revaluation of Dionysius of Halicarnassus' treatise.

ABSTRACT: This work is oriented by three objectives: the presentation of the De Compositione Verborum and of Dionysius of Halicarnassus; the discussion of some issues referring to the criticism of the treatise; and the questioning of concepts such as literature, rhetoric and literary criticism. The shortage of studies on Dionysius' treatise in Brazil justifies the first objective. It should be pointed out that this treatise called much attention from man like Racine and Boileau, and even more so from the European helenists. The second objective becomes relevant due to the discomfort that evolves from the reading of studies on Dionysius' work upon which scholars have imposed questionable charges that show a certain decompass between the expectations of our days and the needs of that time. Finally, the third objective is justified by the misuse of modern concepts in the study of ancient texts. Once the proposed objectives are fulfilled, it is possible to reconsider the De Compositione Verborum pointing out its qualities and contributions.

KEY WORDS: Dionysius of Halicarnassus; De compositione uerborum; rhetoric; literature; criticism. 